\title{
ANALISIS PENGARUH PERUBAHAN BEBAN PADA MOTOR SINKRON 3 PHASA DENGAN VIRTUAL INSTRUMENT
}

\author{
Nurul Huluq \\ Prodi Teknik Elektro UNPAM \\ Jln. Puspiptek Raya No 46 Buaran, Setu - Tangerang Selatan 15310 INDONESIA \\ Email: dosen00928@unpam.ac.id
}

\begin{abstract}
ABSTRAK
Motor sinkron tiga phasa merupakan jenis motor listrik yang banyak digunakan didunia industri karena kehandalannya terhadap pengaruh perubahan beban yang bervariasi. Kehandalan motor sinkron ini dapat dilihat di beberapa pengukuran dengan alat ukur analog maupun digital, hanya untuk menganalisa lebih lanjut terdapat kesulitan tanpa adanya tampilan hasil pengukuran yang dpat divisualkan. Oleh sebab itu tujuan dari penulisan ini adalah untuk menampilkan semua pengukuran baik tegangan, arus, frekwensi dan lainnya kedalam sebuah computer atau PC agar mempermudah dalam menganalisa pengaruh perubahan beban yang terjadi pada motor sinkron tiga phasa. Rangkaian pengujian ini menggunakan komponen utama berupa NImyDAQ (virtual instrument) sebagai hardware nya dan NILabVIEW sebagai software dan komputer sebagai sebuah interface. Dari hasil perancangan rangkaian ini diperoleh data yang tidak menyimpang jauh dengan hasil pengukuran secara analog maupun digital. Selain data hasil pengukuran yang tidak jauh berbeda juga ditampilkan berupa gambar pengukuran, sehingga menunjukkan bahwa alat NImyDAQ dapat memudahkan dalam menganalisa hasil dari pengukuran secara akurat.
\end{abstract}

Kata kunci : motor sinkron tiga phasa, NImyDAQ, NILabVIEW

\begin{abstract}
Analysis of Influence of Change Load on $3^{\text {rd }}$ Phase sync Motor With Virtual Instrument. Three phase phase synchronous motor is a type of electric motor that is widely used in the industry because of its reliability against the influence of varied load changes. The reliability of these synchronous motors can be seen in several measurements with analog and digital measuring devices, only to further analyze the difficulty without the display of measurable results. Therefore, the purpose of this paper is to display all measurements of voltage, current, frequency and other into a computer or $P C$ to facilitate in analyzing the effect of load changes that occur in three phase sync motor. This series of tests uses the main component of NImyDAQ (virtual instrument) as its hardware and NILabVIEW as software and computer as an interface. From the results of this circuit design obtained data that does not deviate far from the measurement results analog or digital. In addition to the measurement data that is not much different also displayed in the form of measurement images, thus indicating that NImyDAQ tool can facilitate in analyzing the results of the measurement accurately.
\end{abstract}

Keywords: three phase sync motor, NImyDAQ, NILabVIEW 


\section{PENDAHULUAN}

Didalam dunia industri dibutuhkan sebuah alat penggerak yang dapat bekerja secara konstan terhadap pengaruh perubahan beban yang bervariasi. Komponen penggerak yang sering digunakan adalah motor sinkron tiga phasa. Motor ini memiliki kelebihan dibandingkan dengan motor lainnya, motor ini memiliki kecepata putar yang cenderung stabil meskipun beban yang terhubung berubah-ubah. Hanya saja hingga saai ini kelebihan dari motor sinkron ini tidak dapat diperlihatkan karakteristiknya secara akurat, hanya berupa angka pengukuran dari peralatan analog maupun digital tanpa adanya tampilan berupa gambar yang ditampilkan di layar computer, sehingga untung mengetahui faktor daya yang mengalir ke motor ini leading atau lagging harus membandingkan angka yang tertera pada alat ukur tersebut. Dikarenakan peralatan yang dipakai relatif mahal harganya maka alat ukur tersebut masih banyak dipakai di dunia industri hingga saat ini. Berbeda dengan kebutuhan penelitian, untuk dapat membuat suatu analisis suatu peralatan yang akurat diperlukan data yang dapat diamati dengan mudah dan dapat divisualkan dengan bantuan HMI. Oleh sebab itulah dibutuhkan suatu perangkat multi fungsi yang dapat mengukur dan menampilkan lebih dari satu parameter kelistrikan, dan dipilihlah NImyDAQ dari national instrument sebuah perangkat yang dapat mengukur: tegangan, arus, frekwensi, kecepatan putar rotor (RPM) dan lain sebagainya,dan menampilkannya ke dalam sebuah computer baik berupa gelombang atau sinyal lainnya dengan labview sebagai software nya. Dengan adanya tampilan yang dapat divisualkan secara akurat maka untuk menganalisa suatu rangkaian akan sangat mudah diamati tanpa harus menghitung kembali berdasarkan angka yang ditampilkan disetiap alat ukur.

\section{TEORI}

\section{Motor sinkron 3 phasa}

Motor Sinkron adalah mesin sinkron yang digunakan untuk mengubah energi listrik menjadi energi mekanik. Mesin sinkron mempunyai kumparan jangkar pada stator dan kumparan medan pada rotor. Kumparan jangkarnya berbentuk sama dengan mesin induksi, sedangkan kumparan medan mesin sinkron dapat berbentuk kutub sepatu (salient) atau kutub dengan celah udara sama rata (rotor silinder). Arus searah (DC) untuk menghasilkan fluks pada kumparan medan dialirkan ke rotor melalui cincin dan sikat.

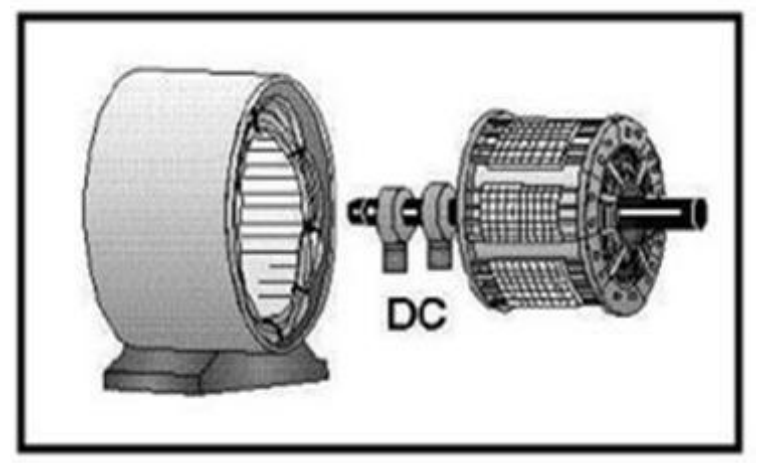

Gambar 1. Motor sinkron

Motor sinkron ini memiliki prinsip kerja yang berbeda ketika terjadinya torsi dan dapat dijelaskan sebagai berikut: apabila kumparan jangkar (pada stator) dihubungkan dengan sumber tegangan tiga fasa maka akan mengalir arus tiga fasa pada kumparan. Arus tiga fasa pada kumparan jangkar ini menghasilkan medan putar homogen (BS). Berbeda dengan motor induksi, motor sinkron mendapat eksitasi dari sumber DC eksternal yang dihubungkan ke rangkaian rotor melalui slip ring dan sikat. Arus DC pada rotor ini menghasilkan medan magnet rotor (BR) yang tetap. Kutub medan rotor mendapat tarikan dari kutub medan putar stator hingga turut berputar dengan kecepatan yang sama (sinkron). Torsi yang dihasilkan motor sinkron merupakan fungsi sudut torsi ( $\delta$ ). Semakin besar sudut antara kedua medan magnet, maka torsi yang dihasilkan akan semakin besar seperti persamaan di bawah ini. 


\section{$T=k . B R . B n e t \sin \delta$}

\section{Dimana:}

Bnet $=$ Resultan medan magnet rotor

$\mathrm{T}=$ Torsi motor sinkron

$\mathrm{K}=$ Konstanta

$\mathrm{BR}=$ Medan magnet rotor

$\delta=$ Sudut kopel

Berikut adalah gambar terjadinya torsi pada motor sinkron ketika tanpa beban dan kita mendapatkan beban:

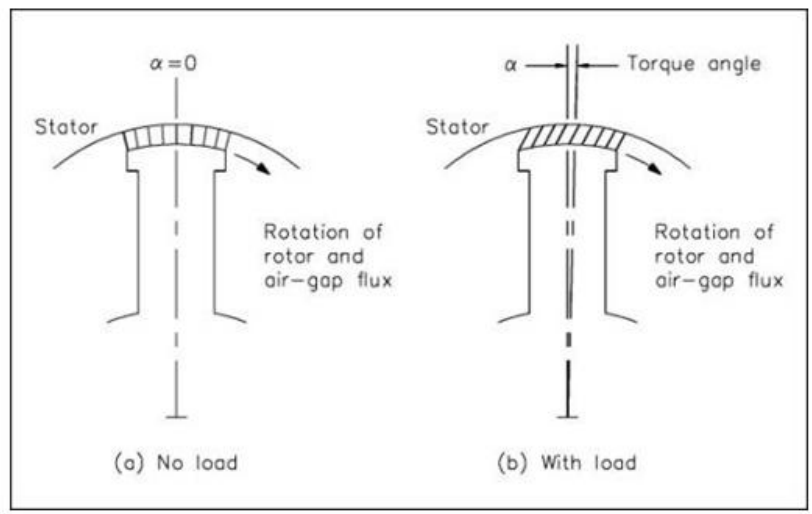

gambar 2. Sudut torsi motor sinkron

Pada beban nol, sumbu kutub medan putar berimpit dengan sumbu kumparan medan . Setiap penambahan beban membuat medan motor "tertinggal" dari medan stator, berbentuk sudut kopel ( $\delta$ ); untuk kemudian berputar dengan kecepatan yang sama lagi. Beban maksimum tercapai ketika $\delta=\angle 90^{\circ}$. Penambahan beban lebih lanjut mengakibatkan hilangnya kekuatan torsi dan motor disebut kehilangan sinkronisasi. Oleh karena pada motor sinkron terdapat dua sumber pembangkit fluks yaitu arus bolakbalik (AC) pada stator dan arus searah (DC) pada rotor, maka ketika arus medan pada rotor cukup untuk membangkitkan fluks (ggm) yang diperlukan motor, maka stator tidak perlu memberikan arus magnetisasi atau daya reaktif dan motor bekerja pada faktor daya $=$ 1,0. Ketika arus medan pada rotor kurang (penguat bekurang), stator akan menarik arus magnetisasi dari jala-jala, sehingga motor bekerja pada faktor daya terbelakang

Nurul Huluq (lagging). Sebaliknya bila arus pada medan rotor berlebih (penguat berlebih), kelebihan fluks (ggm) ini harus diimbangi, dan stator akan menarik arus yang bersifat kapasitif dari jala-jala, dan karenanya motor bekerja pada faktor daya mendahului (leading). Dengan demikian, faktor daya motor sinkron dapat diatur dengan mengubah-ubah harga arus medan (IF).

Pengaruh perunahan beban pada motor sinkron tiga phasa. Jika beban dihubungkan pada motor sinkron, maka motor akan membangkitkan torsi yang cukup untuk menjaga motor dan bebannya berputar pada kecepatan sinkron. Misalnya mula-mula motor sinkron beroperasi pada faktor daya mendahului (leading). Jika beban pada motor dinaikkan, putaran rotor pada asalnya akan melambat. Ketika hal ini terjadi, maka sudut torsi (d) menjadi lebih besar dan torsi induksi akan naik. Kenaikan torsi induksi akan menambah kecepatan rotor, dan motor akan kembali berputa pada kecepatan sinkron tapi dengan sudut torsi (d) yang lebih besar.

\section{Virtual instrument}

Virtual instrument adalah sebuah perangkat lunak dan perangkat keras, untuk menciptakan user-defined sistem pengukuran, yang terdiri dari komponen hardware, seperti multimeter digital, dan oscilloscope yang benar-benar khusus untuk stimulus analisis, atau fungsi pengukuran. Karena fungsi system ini lebih terbatas dalam fleksibilitas daripada system instrumentasi virtual. Perbedaan utama antara instrumentasi hardware dan instrumentasi virtual adalah perangkat lunak yang digunakan untuk menggantikan sejumlah besar perangkat keras.

Pada virtual instrument ini memiliki beberapa tahapan untuk melakukan suatu pengukuran, dan tahapan-tahapan itu antara lain:

1. Perangkat pengukuran analog

2. Akuisisi data dan perangkat pengolahan

3. Pemprosesan digital

4. Distribusi Virtual Instrument

5. 


\section{LabVIEW}

LabView adalah sebuah software yang menpunyai pemograman yang diproduksi oleh Nasional instrument dengan konsep yang berbeda. seperti bahasa pemograman lainnya yaitu $\mathrm{C}++$, Matlab dan Visual basic. LabView juga mempunyai beberapa fungsi dan peranan yang sama, perbedaannya bahwa LabView menggunakan bahasa pemograman berbasis grafis atau blok diagram sementara bahasa pemograman lainnya menggunakan bahasa text.

Program LabView dikenal dengan sebutan $\mathrm{VI}$ atau virtual instruments karena penampilan dan operasinya dapat meniru sebuah instrument pada LabVIEW, user pertamatama membuat user interface atau front panel dengan menggunakan control peralatan input lainnya sedangkan yang dimaksud dengan indikator adalah grafik, led dan peralatan display lainnya. Setelah menyusun user interface, lalu user menyusun blok diagram yang berisi kodekodeVls untuk mengontrol front panel. Software LabView terdiri dari tiga komponen utama yaitu:

\section{Front panel.}

Front panel adalah bagian window yang berlatar belakang belakang abu-abu serta mengandung control dan indiktor. Front panel digunakan untuk membangun sebuah $\mathrm{VI}$, menjalankan program dan mendebug program.

\section{Control dan functions pallete}

Control dan functions pallete digunakan untuk membangun sebuah Vi. Control pallete merupakan tempat beberapa control dan indikator pada front panel, control pallete hanya tersedia di front panel, untuk menampilkan control pallete dapat dilakukan dengan mengklik window>> show control pallete atau klik kanan pada front panel. Contoh control pallete dapat dilihat pada gambar dibawah ini:

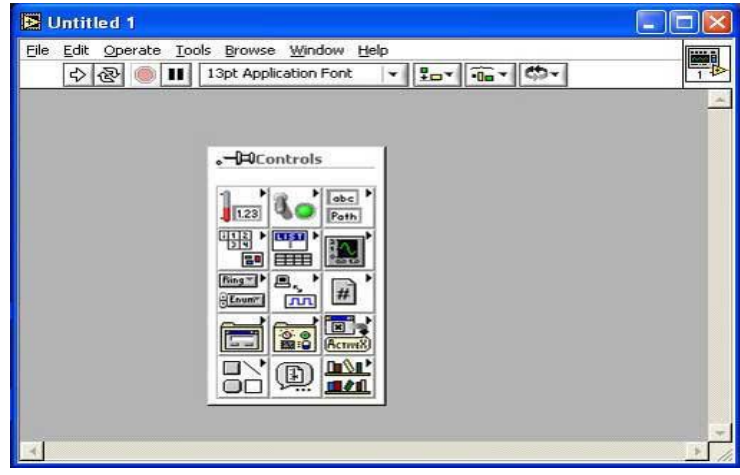

Gambar 3. Control Pallete

\section{NImyDAQ}

NImyDAQ adalah suatu alat akuisisi data portable dengan biaya rendah, penggunaan perangkat MayDAQ menggunakan LabVIEW sebagai basis softwarenya. MyDAQ dapat digunakan oleh para siswa untuk mengetahui cara mengukur dan menganalisis secara real suatu signal yang ada pada alam sekitarnya, MyDAQ dengan ukuran yang portable memungkinkan dalam pengukuran dan menganalisis dapat dilakukan dimana saja dan kapan saja, sehingga dengan mudah untuk digunakan.

Pada MyDAQ terdapat beberapa aksesoris yang dapat digunakan untuk mendukung dalam pengukuran dan analisis diantaranya:

1. Analog

Input.

Ada dua saluran analog input pada MyDAQ, saluran ini dapat dikonfigurasikan baik sebagai impendance differensial tegangan input atau input audio, input analog multiplexing yang berarti satu analog kedigital converter(ADC) untuk digunakan sebagai sampel kedua saluran. Kita dapat mengukur sinyal sampai $\pm 10 \mathrm{~V}$ dalam mode audio, terdapat dua saluran audio yang merupakan jalur stereo input kiri dan kanan. Analog input dapat diukur sampai dengan

$200 \mathrm{kS} / \mathrm{s}$ persaluran yang berguna untuk akuisisi wavefrom. 


\section{Analog Output.}

Ada dua saluran output analog pada MyDAQ

, saluran ini dapat di konfigurasikan baik sebagai tegangan output atau output audio, kedua saluran ini memiliki konverter digital ke analog khusus(DAC). Pada analog output ini menghasilkan sinyal $\pm 10 \mathrm{~V}$ dalam bentuk mode audio dan dua saluran output yang mewakili stereo kiri dan kanan, keluaran analog dapat diperbaharui sampai dengan

$200 \mathrm{kS} / \mathrm{s}$ per saluran. Keluaran analog dapat digunakan dalam ELVISmxfungsi generator dan bode instrument analyzer.

3. Digital input/Digital

output.

Ada delapan line digital input/digital output(DIO) pada MyDAQ, setiap line adalah antar muka/interface fungsi diprogram (PFI) artinya dapat dikonfigurasi sebagai perangkat lunak untuk digital input dan digital output atau dapat bertindak sebagai fungsi masukan dan keluaran. Analog input/Analog output dan Digital input/Digital output dapat dilihat pada gambar dibawah ini :

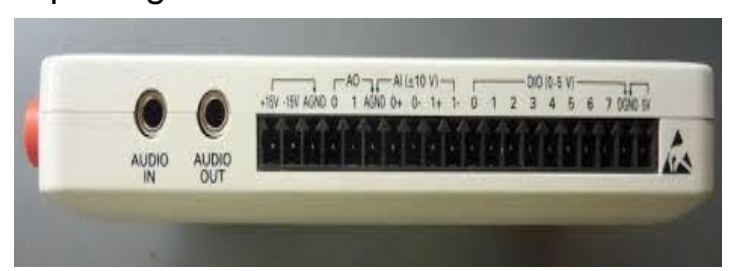

Gambar 4. Analog input/output dan digital input/output

\section{METODOLOGI}

Metode penelitian dilakukan dengan mengacu pada pendahuluan, yang mana penelitian dilakukan dengan membandingkan alat ukur analog dan digital dengan peralatan utama NImyDAQ. Setelah gambar wiring diagram selesai dibuatlah rangkaiannya dengan menggunakan alat ukur analog / digital, untuk pengukuran menggunakan NImyDAQ terlebih dahulu membuat rangkaian yang ada pada blok diagram dan wiring diagram dibuat dan dirangkai sesuai dengan gambar blok diagram dengan terhubung ke alat bantu trafo tegangan dan trafo arus yang terhubung ke komputer seperti gambar berikut:

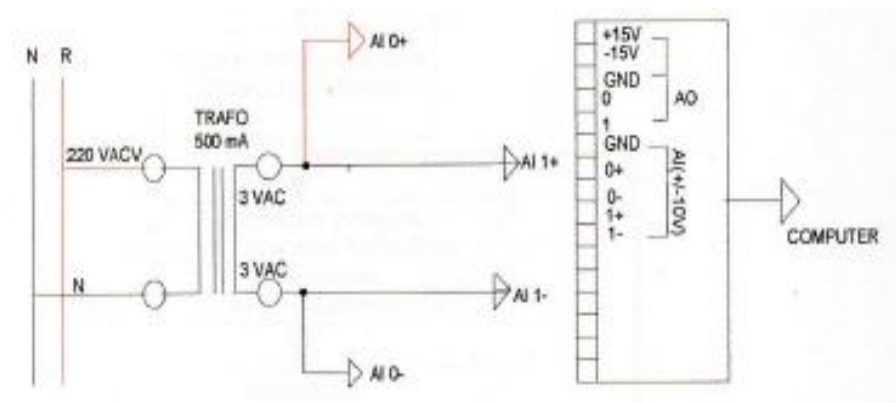

Gambar 5. Rangkaian pengukuran tegangan

Rangkaian pengukuran tegangan tidak dapat dilakukan secara langsung terhubung ke NImyDAQ, karena batas maksimal tegangan input hanya $10 \mathrm{~V} A C$, maka tegangan harus diturunkan terlebih dahulu.

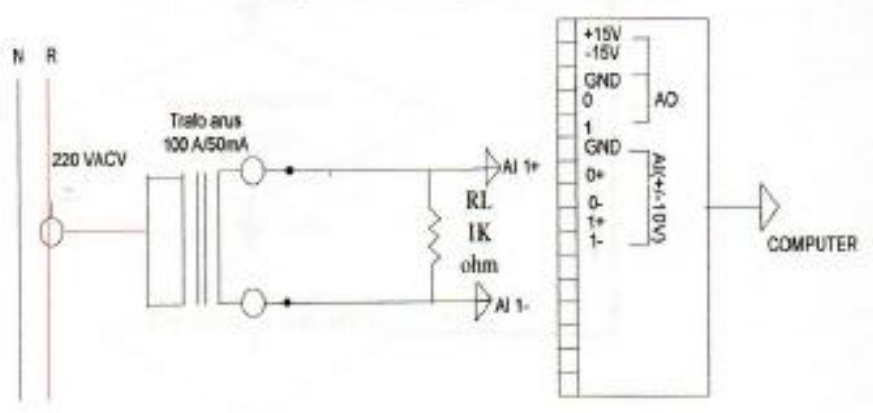

Gambar 6. Rangkaian pengukuran arus

Begitu pula untuk pengukuran arus diperlukan sensor arus atau trafo arus untuk pembacaan arus sebelum masuk ke NImyDAQ kemudian di visualisasikan ke komputer atau PC. 
14. 1 unit NImyDAQ

\section{Diagram alir antar muka}

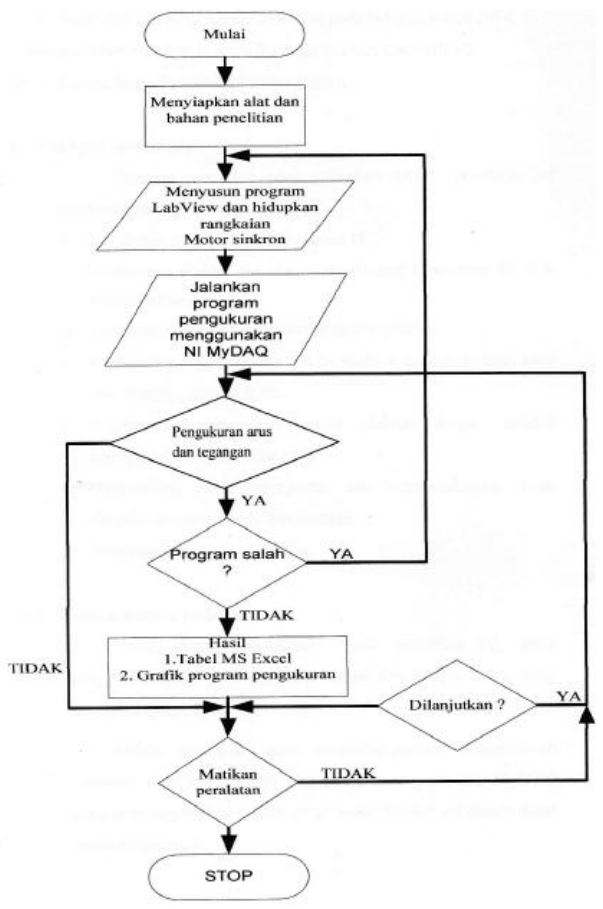

Gambar 7. Flow chart

\section{Waktu dan tempat}

Penelitian dan pengukuran dilakukan pada bulan Februari 2018, dilakukan di laboratorium elektronika Balai Latihan Kerja (BLK) Dinas Tenaga Kerja Tangerang Selatan, Banten.

\section{Alat dan Bahan}

Didalam penelitian ini membutuhkan beberapa alat bantu dan bahan seperti berikut:

1. 1 unit MCB 3 phasa

2. 1 unit stabilizer DC $240 \mathrm{~V} / 6 \mathrm{~V}$

3. 2 unit saklar On/Off 3 kutub

4. 1 unit tombol tekan

5. 1 unit rem bubuk magnetic

6. 1 unit kopling pengaman

7. 1 unit tacho generator

8. 1 unit motor sinkron SP 0.3

9. 4 unit RMS meter

10. 1 unit power meter

11. 1 unit power faktor meter

12. 3 unit trafo penurun tegangan

13. 3 unit trafo arus

\section{Rangkaian pengukuran}

Sebelum dilakukan pengukuran menggunakan NImyDAQ maka rangkaian terlebih dahulu dirangkai menggunakan alat ukur analog dan digital, baru kemudian melakukan pengukuran yang serupa pada lokasi yang sama dengan menghubungkan ke computer melalui NImyDAQ, seperti terlihat pada gambar berikut:

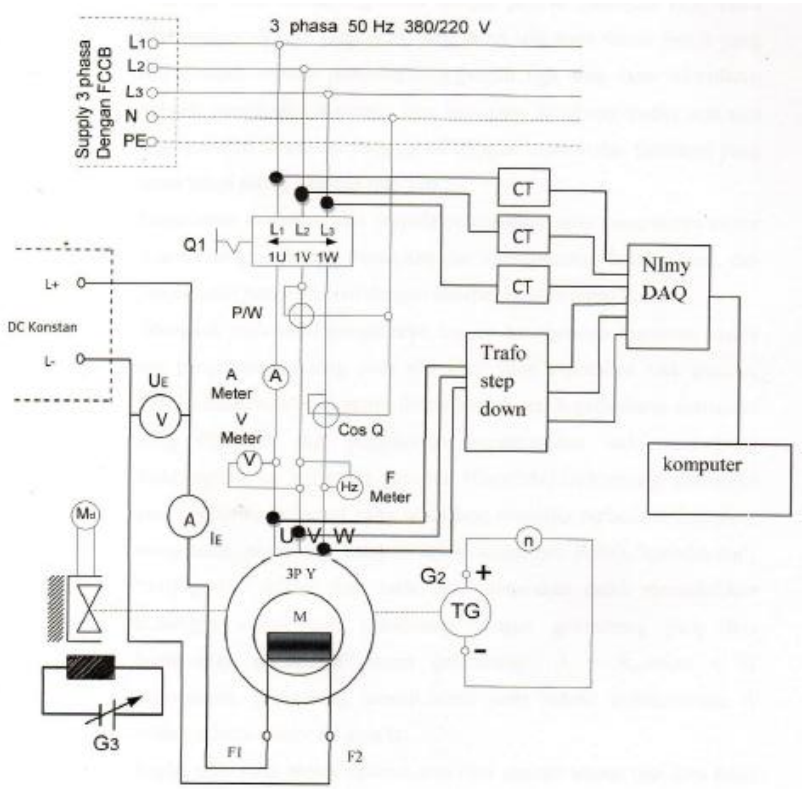

Gambar 8. Skema pengukuran motor sinkron

\section{HASIL DAN PEMBAHASAN}

Pada pengukuran ini membandingkan antara hasil pengukuran menggunakan alat ukur analog dengan NImyDAQ dalam satuan PU. Berikut hasil pengukuran yang telah dilakukan menggunakan kedua alat diata dengan satuan PU

Tabel 1 pengukuran arus dan tegangan phasa-netral terhadap torsi beban pada eksitasi ditetapkan (menggunakan alat ukur analog dalam satuan PU)

\begin{tabular}{|l|l|l|l|l|}
\hline $\mathrm{M} / \mathrm{Nm}$ & $\mathrm{R}(\mathrm{I}-\mathrm{PU})$ & $\mathrm{R}(\mathrm{V}-\mathrm{PU})$ & $\mathrm{S}(\mathrm{V}-\mathrm{PU})$ & $\mathrm{T}(\mathrm{V}-\mathrm{PU})$ \\
\hline 0 & 1,279 & 1,017 & 1,017 & 1,013 \\
\hline 0,3 & 1,325 & 1,008 & 1,008 & 1,008 \\
\hline 0,4 & 1,511 & 1 & 1 & 1,004 \\
\hline 0,5 & 1,511 & 0,995 & 0,995 & 1 \\
\hline 0,6 & 1,558 & 0,991 & 0,991 & 0,995 \\
\hline 0,7 & 1,441 & 0,986 & 0,986 & 0,991 \\
\hline 0,8 & 1,395 & 0,982 & 0,991 & 0,991 \\
\hline 0,9 & 1,604 & 0,986 & 0,986 & 0,991 \\
\hline
\end{tabular}

Nurul Huluq 
Tabel 2 pengukuran arus dan tegangan phasa - netral terhadap torsi beban pada eksitasi ditetapkan (menggunakan NImyDAQ dalam satuan PU)

\begin{tabular}{|l|l|l|l|l|}
\hline $\mathrm{M} / \mathrm{Nm}$ & $\mathrm{R}(\mathrm{I}-\mathrm{PU})$ & $\mathrm{R}(\mathrm{V}-\mathrm{PU})$ & $\mathrm{S}(\mathrm{V}-\mathrm{PU})$ & $\mathrm{T}(\mathrm{V}-\mathrm{PU})$ \\
\hline 0 & 2,061 & 1,562 & 1,550 & 1,214 \\
\hline 0,3 & 2,081 & 1,554 & 1,486 & 1,113 \\
\hline 0,4 & 2,121 & 1,492 & 1,543 & 1,142 \\
\hline 0,5 & 2,146 & 1,465 & 1,503 & 1,062 \\
\hline 0,6 & 2,006 & 1,494 & 1,511 & 1,175 \\
\hline 0,7 & 2,316 & 1,502 & 1,452 & 0,893 \\
\hline 0,8 & 2,406 & 1,462 & 1,507 & 0,892 \\
\hline 0,9 & 2,346 & 1,419 & 1,494 & 1,410 \\
\hline
\end{tabular}

\section{Analisa pembahasan}

Hasil pengukuran yang telah dilakukan pada gambar 8 dan hasilnya terlihat pada tabel 1 dan 2, maka diperoleh data-data yang memiliki selisih tidak terlalu jauh seperti terlihat besarnya arus yang mengalir pada phasa $R$ selisihnya tidak melebihi angka satu amper PU. Selisih yang lebih kecil ditunjukkan pada besarnya nilai tegangan yang berada dibawah 0,5V PU. Dalam hal ini seperti yang telah dipaparkan pada teori diatas bila arus pada medan rotor berlebih (penguat berlebih), kelebihan fluks (ggm) ini harus diimbangi, dan stator akan menarik arus yang bersifat kapasitif dari jala-jala, dan karenanya motor bekerja pada faktor daya mendahului (leading). Dengan demikian, faktor daya motor sinkron dapat diatur dengan mengubah-ubah harga arus medan (IF) seperti terlihat pada gmbar 9 berikut:

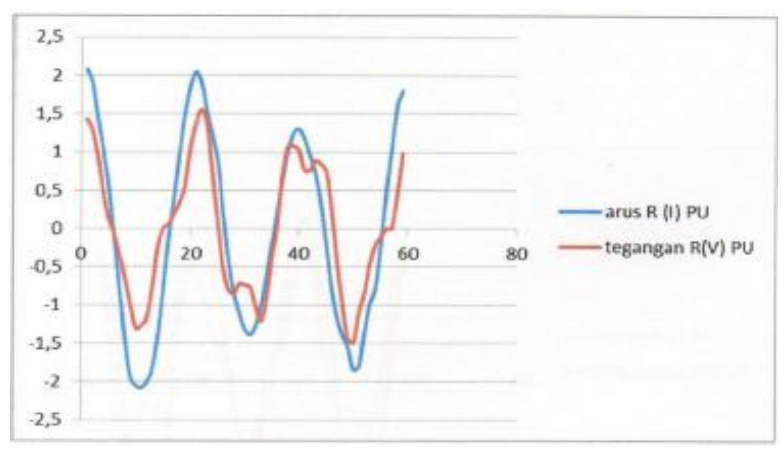

Gambar 9. Gelombang sinus antara arus dan tegangan phasa $R$ dengan torsi $0,3 \mathrm{~N}(\mathrm{Nm})$

\section{KESIMPULAN}

Berdasarkan dari hasil pengukuran dan perhitung tentang pengaruh perubahan beban pada motor sinkron tiga phasa terhadap beberapa variasi beban maka dapat disimpulkan sebagai berikut:

1. Jika beban dihubungkan pada motor sinkron, maka motor akan membangkitkan torsi yang cukup untuk menjaga motor dan bebannya berputar pada kecepatan sinkron.

2. Kecilnya nilai selisih antara hasil pengukuran secara analog dengan menggunakan NImyDAQ menunjukkan bahwa alat ini memiliki

kehandalan lebih untuk dimanfaatkan dalam pengukuran 3 phasa.

3. Pengukuran dilakukan menggunakan alat ukur yang telah mendapat sertifikasi Kalibrasi Nasional (sertifikat terlampir)

\section{UCAPAN TERIMAKASIH}

Puji syukur saya ucapkan kepada Alloh SWT yang maha esa atas selesainya penelitian ini, pada kesempatan ini penulis ingin mengucapkan terima kasih kepada:

1. Bapak DR.H.Dayat Hidayat, M.M selaku Rektor Universitas Pamulang.

2. Bapak IR.Dadang Kurnia, M.M selaku Dekan Fakultas Teknik Universitas Pamulang.

3. Bapak Syaiful Bakhri, S.T., M.Eng.Sc.,PhD. selaku Ketua Jurusan Teknik Elektro Universitas Pamulang.

4. Ibu Faraida Nafiri. Selaku Dosen pembimbing I yang dengan sabar dan senantiasa membimbing dan menyarankan penulisan penelitian ini. 


\section{IDAFTAR PUSTAKA}

1. National instruments, NImyDAQ online 2013.

2. Wildi Theodore, "Electrical Machines", Drives And Power System", Pretica Hall International, Liverpool, 1983.
3. Wijaya, Mochtar, Dasar-dasar Mesin Listrik, Penerbit Djambatan, Jakarta 2001.

4. Zuhal, Dasar Teknik Tenaga Listrik Dan Elektronika Daya, Edisi ke 5, Gramedia, Jakarta, 1995.

5. Www.kilowattclassroom.com/arcive/sy ncmotors.pdf. 